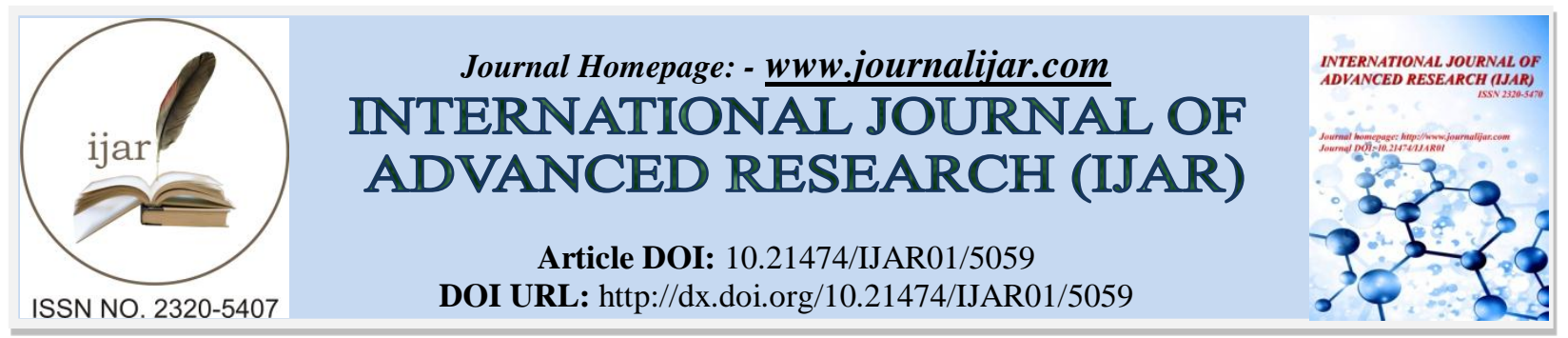

RESEARCH ARTICLE

\title{
THE CONTRIBUTION OF THE FRACTIONNAL FLOW RESERVE IN THE CONFIRMATION OF MYOCARDIAL ISCHEMIA REVEALED BY VENTRICULAR RYTHM DISORDERS: REPORT ON TWO CASES AND A LITERARY REVIEW.
}

\author{
Mingou JS ${ }^{1}$, Dioum $M^{3}$, Ndao SCT ${ }^{1}$, Zabalawi $A^{2}$, Delaunay $R^{2}$, Taldir $G^{2}$, Bodi $S^{2}$, Payot $L^{2}$, Diao $M^{1}$ and \\ Moquet $\mathrm{B}^{2}$. \\ 1. Department of Cardiology, Aristide Le Dantec Hospital University, Dakar, SENEGAL. \\ 2. Department of Cardiology, Yves Le Foll Hospital, Saint Brieuc, FRANCE. \\ 3. Department of Cardiology, Fann Hospital University, Dakar, SENEGAL.
}

\section{Manuscript Info}

\section{Manuscript History}

Received: 03 June 2017

Final Accepted: 05 July 2017

Published: August 2017

\section{Key words:-}

Myocardial ischemia, intermediary stenosis, FFR

\begin{abstract}
The past few years, a large amount of proofs has shown that angiography, used alone, presents limits for determining the physiologic meaning of coronary stenosis, mostly when they are intermediary[1]. Angiography, with the physiological study using the Fractionnal Flow Reserve (FFR), has prouved it's efficacy with the reduction of cardiovascular events compared to Angioplasty guides by Angiography alone[2-5]. This approach using the FFR, in the management of stable coronary diseases, benefits from the class IA recommendation in European recommendations[6]. Our goal is to show the importance of the FFR in the determination of the myocardial ischemia reavealed by ventricular rhythm disorders, through these two observations.
\end{abstract}

Copy Right, IJAR, 2017,. All rights reserved.

\section{Introduction:-}

\section{Observation 1:-}

We report the first case, concerning a 78 years-old overweighted man (BMI: 27.9) formerly smoker. Twenty years ago, he underwent a coronary angiography that turned out to be normal. The clinical history can be summarized by the occurence of nausea along with vomiting episodes composed of food, followed by dizziness and faintness without a loss of consciousness or chest pain. In addition to that, he also reported a shortness of breath revolving for months, associated with chronic cough coming with whitish sputum.

The electrocardiogram and the rest cardiac ultrasound did not describe any abnormality.

The long-term implantable Holter Reveal Medtronic had diagnosed a non-sustained polymorphic ventricular tachycardia. The coronary angiography realised via the right radial artery found an intermediary injury (50-60\%) in the right medium coronary (Illiustrations $1 \mathrm{~A}$ and $1 \mathrm{~B})$. The FFR used was functionnaly significant at 0.77 (Illustration 2). A right coronary angioplasty with the implementation of an eluting stent $(3 \times 20 \mathrm{~mm})$ was made (Ilustrations 3, 4A and 4B). 
At the post-angioplasty control, the FFR came négative at 0.82 . Nine months after the procedure, no cardiovascular symptom in the functional level has been reported. The implantable Holter have not noticed any recurrence of the ventricular rhythm disorder.

\section{Observation 2:-}

In a second study, we report the clinical history of a 79 years-old man, who happen to be Hypertensive with Type 2 diabetes recently discovered, presenting episodes of faintness without loss of consciousness.

The rest electrocardiogram noted a left Bundle Branch Block with a heart rate at 42 cales per minutes and negative T-waves in DI and aVL.

The rest Doppler cardiac ultrasound was normal. The stress test showed the induction of a left Bundle Branch Block. The monitoring Holter revealed lots of ventricular extrasystole and a non-frequency dependant sporadic Bunble Branch Block.

The stress cardia ultrasound found frank ventricular hyperexcitability due to stress, along with a lower level of supra-ventricular hyperexcitability without any obvious abnormality of the segmentes kinetics.

A coronary angiography was made in order to explore those rhythm disorders due to stress; the result was an intermediary injury of the proximal portion of the left anterior descending artery (LAD).

The FFR made on that injure on the proximal portion of the LAD was positive at 0.77 motivating the implementation of an eluting stent $(3.5 \times 12 \mathrm{~mm})$. After angioplasty, the FFR control came négative at 0.92 . the electrophysiological exploration of the bundle branch block did not contribue much. The long-term implantable Holter for control after the angioplasty did not show any abnormality.

\section{Discussion and literary review:-}

These two clinical cases perfectly illustrante the difficulty the cardiologie is daily facing with significant intermediary injuries at the angiography. Indeed, mostly, the angiography, alone, cannot permit to know if the injuries are functionally significant, in other words if they necessitate the implementation of stents. The FFR, in the opposite, can solde that problem.

The FFR is defined as the maximal flow ratio between a stenotic artery and that same artery when there is no stenosis[2]. The flow $(\mathrm{Q})$ is determined by the pression gradient divided by the resistance $\mathrm{R}(\mathrm{P}=\mathrm{RQ})$. When the resistances are minimal and constant (maximal hyperaemia), they can be neglected in the FFR calculation which Will now be obtained by the Distal pressure Dp (downstream of the stenosis) on the Proximal pressure Ap (Aortic pressure) during a maximal hyperaemia test. The normal rate is 1 . When the FFR rate is lower than 0.75 it induces invariably an ischemia whereas it never happens when the FFR is higher than $0.8[7,8]$.

Those results are, furthermore, correlated to the non évasive tests (stress test, myocardial scintigraphy, stress cardiac ultrasound)[7]. However, there is a grey area (between 0.75 and 0.80 ) that necessitate to take in account other clinical informations[6].

The FFR is not only associated with the morphology of the injury, but also to the extent of the distal myocardial territory. Hence, the FFR will be considerably lowered in severe injuries with little luminal in arteries in charge of a extended myocardial territory.

More precisely, the diastolic coronary flow is controled by the difference of pressure between the epicardic vessel and the pressure called "zero flow" supposed to be equal to the central venus pressure. In vasodilatation conditions, the microvascular resistances are supposed to be close to zero. Hence, the measured FFR is independant of hemodynamic changes like cardiac rate, the blood pressure or the myocardial contractility [9].

The FFR is mainly used to evaluate the intermediary injuries that we can devine as injuries for which it is hard to appreciate the fonctionnal aspect with angiography and they are mostly called "intermediary, questionnable, moderate and non significant injuries". In the absence of ischemia test or non relevant results, the use of angioplasty 
becomes very biased. In order to avoid useless and potentially dangerous angioplasties, the FFR appears to be a valuable tool. Ultimately, it has been shown that with patients presenting angiographically questionnable stenosis, the FFR was more accurate than stress test, myocardial scintigraphy and stress ultrasound to study the hemodynamical aspect of that type of injury $[3,4,10]$.

Finally, the FFR is a technique easy to execute routinely at the cost of a quasi void increment of the risk of the procedure and a low extension of the duration of the exploration (generally less than ten minutes) improving by the immédiate response it provides, the deployment of the additional material. The only complementary manipulation technique is the crossing of the target injury by a guide at 0.014 Inch and the induction of a coronary hyperaemia via the injection of a vasodilator in intra-coronary (Papaverine, adenosine) or in intravenous [11,12,13]. The result is, therefore, directly obtained in the catheterization Laboratory and an angioplasty can be realised at the same time if justified [13].

There is always a degree of incertainty in every medical procedure. Yet the FFR has considerably reduced the fonctionnal incertainty based on the old and simple oculo-stenotic approach depending on the angiographic morphological value higher than $50 \%$, established in 1974 by Gould and used ever since routinely [14].

\section{Conclusion:-}

The FFR is a very user-friendly, reliable and accurate tool, permitting to study in the catheterization Laboratory the significant physiological aspect of an intermediary stenosis in the epicardial coronary.

The therapeutic sanction based of the FFR has prouved it's benefit in many clinical trials. This tool helps the cardiologist making a suitable decision in the context of intermidiary injuries, especially in the catheterization Laboratory.

\section{Illustrations:-}

Illustrations 1A and 1B: Coronary angiography via the right radial artery; intermediary stenosis of the right middle corornary artery, left coronary artery structures without any significant injury
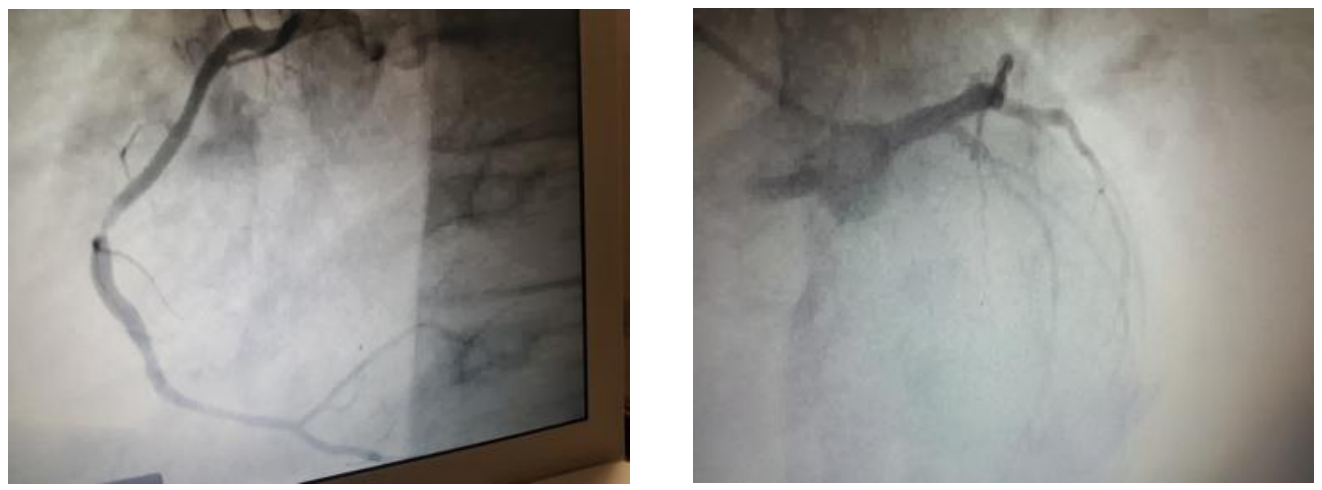
Illustration 2: significant FFR at 0.77 of the right middle coronary artery injury
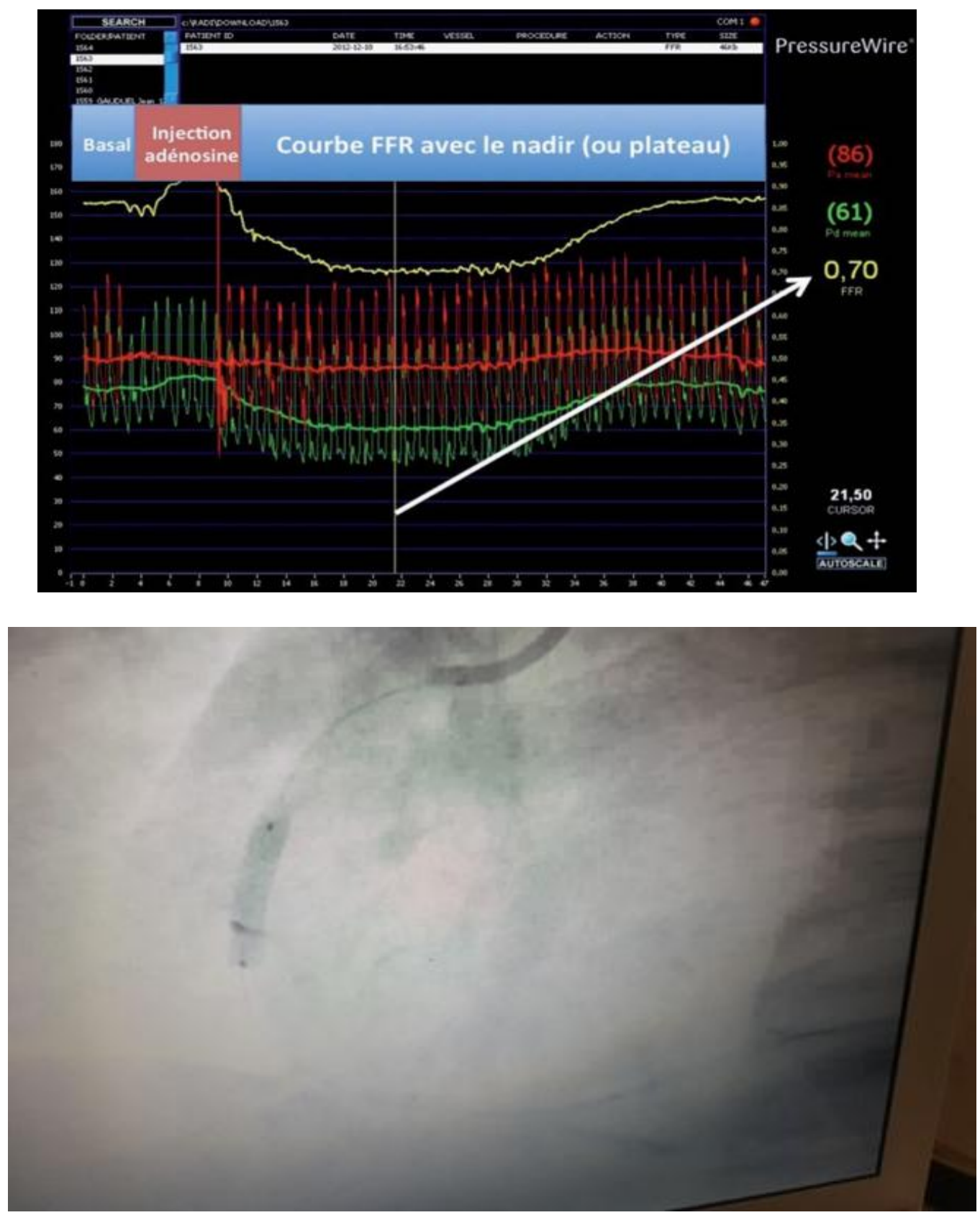

Illustration 3: Implementation of eluting stent $(3 \times 20 \mathrm{~mm})$ 
Illustrations 4A et 4B: Final result after the implémentation of the stent in (right anterior oblique) RAO and (left anterior oblique) LAO
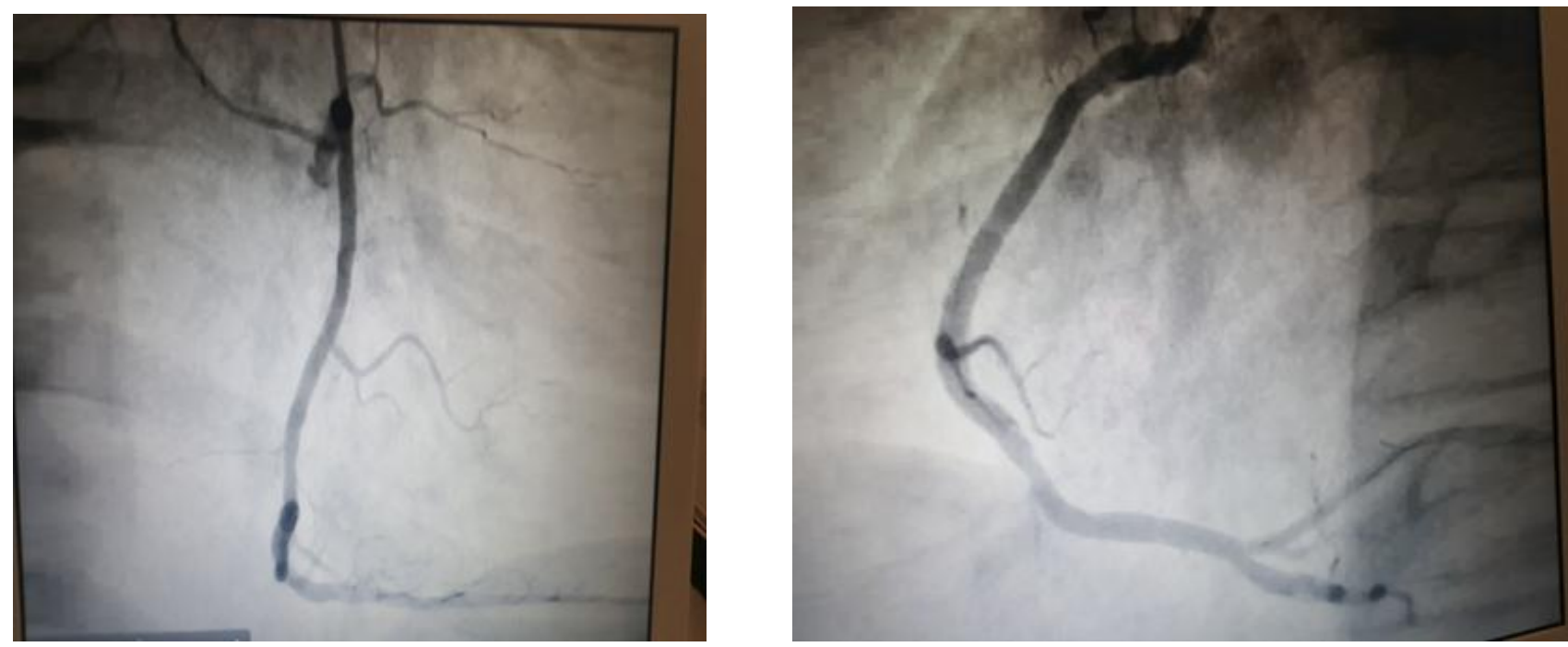

\section{Bibliography:-}

1. White CW, Wright CB, Doty DB et al. Does visual interpretation of the coronary arteriogram pre-dict the physiologic importance of a coronary stenosis? N Engl J Med1984;310(13):819-24.

2. Pijls NHJ, Sels J-WEM. Functional measurement of coronary stenosis.JAmCollCardiol 2012;59(12):1045-57.

3. Pijls NHJ, van Schaardenburgh P, ManoharanG et al. Percutaneous coronary intervention of functionallynonsignificant stenosis: 5-year follow-up of the DEFER study. J Am CollCardiol 2007;49(21):2105-11.

4. Tonino PAL, De Bruyne B, Pijls NHJ et al. Fractional flow reserve versus angiography for guiding percutaneouscoronary intervention. N Engl J Med 2009;360(3):213-24.

5. De Bruyne B, Fearon WF, Pijls NHJ et al.Fractional flow reserve-guided PCI for stable coronary artery disease. NEngl J Med 2014;371(13):1208-17.

6. Authors/Task Force members, Windecker S, Kolh P, Alfonso F et al. 2014 ESC/EACTS Guidelines on myocardial revascula-rization: The task force on myocardial revascularization of the EuropeanSociety of Cardiology (ESC) and the European Association for Cardio-Thoracic Surgery (EACTS)*developed with the special contribution ofthe European Association of Percutaneous Cardiovascular Interventions(EAPCI). Eur Heart J 2014;35(37):2541-619.

7. Measurement of fractional flow reserve to assess the functional severity ofcoronary-artery stenoses. 1996;334(26):1703-1708.

8. Pijls NH, Van Gelder B, Van der Voort P et al. Fractional flow reserve. A useful index to evaluate the influenceof an epicardial coronary stenosis on myocardial blood flow.Circulation1995;92(11):3183-93.

9. Ladwiniec A, Hoye A. The haemodynamic effects of collateral donationto a chronic total occlusion: implications for patient management. Int JCardiol 2015;198:159-66.

10. Picard F, Tadros VX, Pighi M et al Fractional flow reserve(FFR) et instantaneouswave-free ratio (iFR),l'évaluation physiologique d'une sténose coronarienne dans le laboratoire decatéthérisme cardiaque : mise au point et guide pratique. Ann CardiolAngeiol (Paris) (2016), http://dx.doi.org/10.1016/j.ancard.2016.03.002

11. Casella G, Leibig M, Schiele TM, et al. Are high doses of intracoronary adenosine an alternative to standard intravenous adenosine for the assessment of fractional flow reserve? Am Heart J 2004;148:590-5.

12. Rioufol G, Caignault JR, Finet G, et al. 150 Microgram intracoronary adenosine bolus is mandatory for accuratefractional flow reserve measurement in intermediate lesions: a dose-ranging study. EuroIntervention2005;1:204-207.

13. Finet G, Rioufol G. la FFR. AMCVP-09-2013. Vol 19, 220.p 23-25

14. Gould KL, Lipscomb K, Hamilton GW, et al. Physiologic basisfor assessing critical coronary stenosis. Am J Cardiol1974;33:87-94 